\title{
Obstacles Face Nursing Staff Toward Care of Critically Ill Obese Patient in Intensive Care Units
}

\author{
Fatima Khamis Baqraf ${ }^{1}$, Mona Aly Mohammed ${ }^{2}$ \& Asmaa Aly Mahgoub ${ }^{3}$. \\ 1. Academic instructor of critical care and emergency Nursing department Faculty of nursing Hadhramout University \\ in Yemen. \\ 2. Assistant professor of critical care and emergency Nursing department Faculty of nursing Assuit University, Egypt \\ 3. Assistant professor of critical care and emergency Nursing department Faculty of nursing Assuit University, Egypt
}

\begin{abstract}
Background: Intensive care unit was a stressful environment. Therefore nurses encounter additional obstacles when caring for obese patients in ICU. These obstacles must be identified for proposing a solution and enhancing safe and quality nursing care to critically ill obese patients. The aim of this study was to assess obstacles that face nursing staff toward the care of critically ill obese patients in the intensive care unit. Design: Cross-sectional descriptive research design. Subject: All available critical care nurses and obese patient at Assuit University Hospitals within 6 months. Setting: The study was carried out at General, Trauma, Anesthesia, and Cardiac ICU at Assiut University Hospitals. Two tools were utilized to collect data; a patient assessment sheet and a nurse's self-administered questionnaire about obstacles in the care of critically ill obese patients. Method: Nurses' obstacles during the care of critically ill obese patients about equipment and clinical practice were obtained by using a self-administered questionnaire. The questionnaire was translated by a researcher to Arabic format in order to suit the nurses' language and their level of understanding. Results: Most nurses' obstacles regarding equipment were lack of proper cuff size $76.7 \%$, lifters $66.7 \%$, and bariatric bed $60.0 \%$. According to clinical practice, turning and repositioning $91.1 \%$, blood pressure measurement76.7\%, and calculate calories $67.8 \%$. Conclusions: Nurses' obstacles in the care of critically ill obese patients increase with an increased number of obese patients. Recommendations: Overcome these obstacles are essential in hospitals through the application of new strategies to provide appropriate patients care.
\end{abstract}

\section{Keywords: Critical Care Nurses, Obese Patients \& Care Obstacles.}

\section{Introduction}

Overweight and obesity are defined as abnormal or excessive fat accumulation that presents a risk to health. A crude population measure of obesity is the body mass index (BMI), a person's weight (in kilograms) divided by the square of his or her height (in meters). A person with a BMI of 30 or more is generally considered obese. A person with a BMI equal to or more than 25 is considered overweight. Overweight and obesity are major risk factors for a number of chronic diseases, including diabetes, cardiovascular diseases, and cancer (WHO, 2020).

The intensive care unit poses more detrimental challenges because it has to deal with the lives of patients and providing quality of care to critically ill obese patients. The special needs of the obese or morbidly obese patient should be considered such as adequately prepare for transporting, positioning, and transferring the patient to prevent delays or embarrassment for them. When larger equipment are not available or are stored in a place that suggests infrequent use, it can signal to patients that their size is unusual and that they don't belong. The availability of material and human resources is essential for the proper management of critically ill obese patients. (Malelelo-ndou et al., 2019).

Nursing staff encountered many difficulties in the care of critically ill obese patient ranging from accessing the equipment and basic supplies (eg, gowns), finding additional support and resources to assist with care, accessing clinical information and guidelines, making sound clinical decisions that are evidence-based, stabilizing, monitoring, intervention in an effective way in life-threatening situations, attending to all care needs of critically ill obese patient and providing safe nursing care (Shea \& Gagnon, 2015).

Critical care nurses play an important role in intensive care units to provide optimal care for obese patients. Caring for critically ill obese patients have an impact on many different areas in terms of basic care, moving, handling, length of stay, discharge planning, transportation, resources use, education, training, and nutrition. The numbers of critically ill obese patients were increased, but currently, healthcare organizations don't appear to have any strategic position. This results in difficulties in the planning and commissioning of services and also a lack of support for critical care nurses (Lumley et al., 2015). 
As the prevalence of obesity in the population has increased, therefore trend in hospitalized patients and patients admitted to ICU who are obese and extremely obese were increased. The prevalence of obese patients in critical care varies depending on the population, ranging from $5.4 \%$ in trauma patients, through $17.1 \%$ in postoperative cardiac surgical patients, to almost $25 \%$ of medical/surgical intensive care unit patients. Their admission to critical care units exposes obese patients to an environment that may be unsuited to their special needs. Critically ill obese adults pose unique challenges for critical care nurses and multidisciplinary teams in caring for them ( El Solh, 2012).

Critical care nurses perceived caring for obese patients as emotionally demanding owing to these patients' vulnerability, dissimilarity, and physical challenges compared to normal-weight patients. They experienced ambivalent feelings caring for these patients: while they endeavored to provide good and equal care to all patients, simultaneously feel of frustration arose among them relating to the physically demanding care situations and unwillingness to provide optimal care to the critically ill obese patient (Robstad et al., 2018).

\section{Significance of the study}

From the researcher's clinical experience it has been observed that the number of critically ill obese patients admitted to the intensive care unit was increased and critical care nurse complains of obstacles that they face during care of them. Globally prevalence of obesity has increased from less than $1 \%$ in 1975 to $6-8 \%$ in 2016 , among girls and boys, and from $3 \%$ to $11 \%$ among men and from $6 \%$ to $15 \%$ among women over the same period (Jaacks et al., 2019). Egypt is one of the six countries in the Middle East that show the highest levels of overweight and obesity ranges from $74 \%$ to $86 \%$ in women and from $69 \%$ to $77 \%$ in men on adults aged 15 years or older (Cheyenne \& Michael, 2018). So this study will be carried out in an attempt to collect data to identify critical care nurses' obstacles regarding equipment and clinical practice toward the care of critically ill obese patients across different categories of ICUs.

\section{Aim of the study}

The aim of the study is to assess obstacles that face nursing staff toward the care of critically ill obese patients in intensive care units.

\section{Research questions}

Are there any obstacles regarding equipment face critical care nurses in the care of critically ill obese patient?

Are there any obstacles regarding clinical practices face critical care nurses in the care of critically ill obese patient?

\section{Subject \& Method \\ Research design}

Cross-sectional descriptive research design was used to fulfill the aim of this study.

\section{Research settings}

The study was conducted in general, trauma, cardiac, and anesthesia intensive care units at Assuit University Hospitals.

\section{Sample}

All available critical care nurses (90) who have direct contact with bedside care of the obese patients and purposive sample of all available adult critically ill obese patients (70) to identify obesity degree according to their BMI and to identify chronic illness like hypertension which related to nurses' obstacles regarding equipment and clinical practice during the period of collecting data within 6 months in general, trauma, cardiac, and anesthesia intensive care units at Assuit University Hospitals within six months.

\section{Tools of the study}

Two tools were used in this study.

Tool I: Assessment questionnaire

Part (1): Self-administered questionnaire. It was developed by the researcher to assess nurses' sociodemographic data such as age, sex, educational level, years of experience, working area, marital status, and attended training program about the care of the critically ill obese patient.

Part (2): Patient assessment questionnaire. It was developed by the researcher to assess patients' sociodemographic data such as the unit of admission, age, sex, height, weight, and medical data such as diagnosis, BMI categories, history of chronic diseases, and nutritional condition.

Tool II: - Self-administered questionnaire. It was developed by the researcher after reviewing the relevant literature (Robab, 2017), (Foroozesh et al., 2017) , (Luis, 2016) to assess critical care nurse's opinions about obstacles in the care of critically ill obese patients through the uses of Likert scale. Scores assigned to each item in five points: (1) Strongly disagree; (2) Disagree; (3) Undecided; (4) Agree; (5) Strongly agree. It comprised of three parts: Part one: Obstacles face critical care nurses during the care of critically ill obese patients regarding equipment. It consists of (9) items such as lifters and aids for lifting patients, sphygmomanometers with appropriate cuff size, patient gowns with an appropriate size, bed sheets with an appropriate size, wheelchairs, and chairs with an appropriate size, walkers for obese people, bariatric bed and stretchers. Part two: Obstacles face critical care nurses during the care of critically ill obese patients regarding clinical practices. It consists of (16) items such as turning and repositioning patients on the bed, blood 
pressure measurement, transferring patients between wards, changing clothes, changing bed sheets, weaning the patient from mechanical ventilation.

Part three: Priorities to improve the care of a critically ill obese patient. It consists of (5) items such as the provision of appropriate and adequate comfort and care equipment, use of experienced personnel for a difficult and complicated procedure, a supply of enough personnel for help and providing care to obese patients, training program in care of critically ill obese patients and provides clinical guidelines, practice standards, and other resources to assist critical care nurses in the care of a critically ill obese patient.

\section{Methods}

\section{Validity and reliability}

The content validity of the developed tools were tested by a jury of five specialists in the related fields, three in the field of critical care nursing and two in the field of critical care medicine to assess the clarity, feasibility, applicability, and after that, all the necessary modifications were done.

The reliability of the tools were tested for a questionnaire of critical care nurses' obstacles during care of critically ill obese patients by using $\alpha$ Cronbach's coefficient regarding equipment $r=0.76$, clinical practices $\mathrm{r}=0.73$, and priorities to improve the care of a critically ill obese patient $r=0.9$ which is acceptable.

\section{Pilot study}

A pilot study was conducted on $10 \%$ of the sample (11critical care nurses and 14 patients), who met the predetermined selection criteria to test the applicability of the tools and the time needed for data collection and the necessary modifications were done. The pilot study sample was excluded from the actual study.

\section{Ethical considerations}

The research proposal was approved by the Ethical Committee in the Faculty of nursing. There is no risk for nurses and patients during the application of the study. The study was followed by common ethical principles in clinical research. Oral consent was obtained from ICU nurses and conscious patients or the relatives of comatose patients who participated in the study, after explaining the nature and the purpose of the study. Confidentiality and anonymity were assured. Nurses and patients have the right to refuse to participate and or withdraw from the study without any rational at any time. Nurses' and patients' privacy was considered during the collection of data.

\section{Methods of data collection}

Permission to conduct the study was obtained from the hospital's responsible authority after explanation the aim and nature of the study.
The official approval was obtained from hospital directors and heads of selected intensive care units prior to data collection.

Data collection took six months started from October 2019 till March 2020.

The researcher collects data two to three times a week in the morning and afternoon shifts in the general, cardiac, trauma, and anesthetic units at Assuit University Hospitals.

The purpose of the study was explained to all critical care nurses who were participated in the study and to all conscious patients and the relatives of comatose patients prior to data collection.

The researcher was recorded patients' demographic data and patients' medical data such as diagnosis and history of chronic diseases from a patient clinical sheet and medical record.

The researcher was calculated BMI for patient using the following equation: $-\mathrm{BMI}=\mathrm{W}[\mathrm{kg}] /(\mathrm{H}[\mathrm{m}])^{2}$ ( tool I part 2) WHO, 2020).

The researcher calculated calorie intake and required for a patient to assess the nutritional condition of critically ill obese patients who admitted to intensive care units by using the Harris-Benedict equation.

$\{\mathrm{REE}=66.5+13.75 \times \mathrm{W}+5.003 \times \mathrm{H}-6.775 \times \mathrm{A}$ (for males) $\mathrm{REE}=655.1+9.563 \mathrm{x} \mathrm{W}+1.85 \mathrm{x} \mathrm{H}-4.676 \mathrm{x}$ A (for females) $\}$ (Tool I part 2) W=Weight in $\mathrm{kg}$, $\mathrm{H}=$ Height in $\mathrm{cm}, \mathrm{A}=\mathrm{Age}$ in years (Luy \& Dampil, 2018).

Obstacles face critical care nurses during the care of critically ill obese patients regarding equipment, clinical practices, and priorities was obtained by using a self-administered questionnaire. The questionnaire was translated by the researcher in Arabic format in order to suit the studied nurses' language and their level of understanding.

At begging the researcher was introduce herself to initiate a line of communication.

Critical care nurses' agreement for voluntary participation was obtained and the purpose and nature of the study were explained.

The researcher handed the questionnaire to all participants of critical care nurses and asked nurses to fill out the questionnaire individually at their break time.

The time for completion of the questionnaire was ranged from fifteen to twenty minutes.

\section{Statistical analysis}

Data obtained were reviewed, prepared for computer entry, coded, analyzed, and tabulated. Data analysis was done by using SPSS (Statistical package for social science) version (20) and clearing of data was done. Data analysis was started by descriptive statistics such as frequencies, percentages, means, 
and standard deviation. After that, a nova test was used as a significant test to find out the relationship between critical care nurses' age and obstacles related to equipment. If the result of the p-value was less than 0.05 considered statistically significant.

\section{Result}

Table (1): Distribution of demographic data of studied nurses $(n=90)$.

\begin{tabular}{|c|c|c|}
\hline & No. & $\%$ \\
\hline \multicolumn{3}{|l|}{ Age: (years) } \\
\hline$<24$ & 32 & 35.6 \\
\hline $24-30$ & 56 & 62.2 \\
\hline$>30$ & 2 & 2.2 \\
\hline Mean \pm SD & \multicolumn{2}{|c|}{$25.2 \pm 4.1$} \\
\hline \multicolumn{3}{|l|}{ Sex } \\
\hline Male & 0 & 0 \\
\hline Female & 90 & 100.0 \\
\hline \multicolumn{3}{|l|}{ Marital status } \\
\hline Single & 35 & 38.9 \\
\hline Marriage & 55 & 61.1 \\
\hline \multicolumn{3}{|l|}{ Working experience } \\
\hline Less than4 years & 53 & 58.9 \\
\hline $5-9$ & 19 & 21.1 \\
\hline More than 10 years & 18 & 20.0 \\
\hline \multicolumn{3}{|l|}{ Educational level } \\
\hline Bachelor of Nursing & 14 & 15.6 \\
\hline Nursing Diploma & 57 & 63.3 \\
\hline Technical Institute of Nursing & 19 & 21.1 \\
\hline \multicolumn{3}{|l|}{ Working area } \\
\hline Trauma ICU & 26 & 28.9 \\
\hline General ICU & 22 & 24.5 \\
\hline Cardiac ICU & 21 & 23.3 \\
\hline Anesthesia ICU & 21 & 23.3 \\
\hline \multicolumn{3}{|l|}{ BMI categories } \\
\hline Less than 25 & 52 & 57.8 \\
\hline $25-30$ & 25 & 27.8 \\
\hline More than 30 & 13 & 14.4 \\
\hline
\end{tabular}

\section{Attended training program}

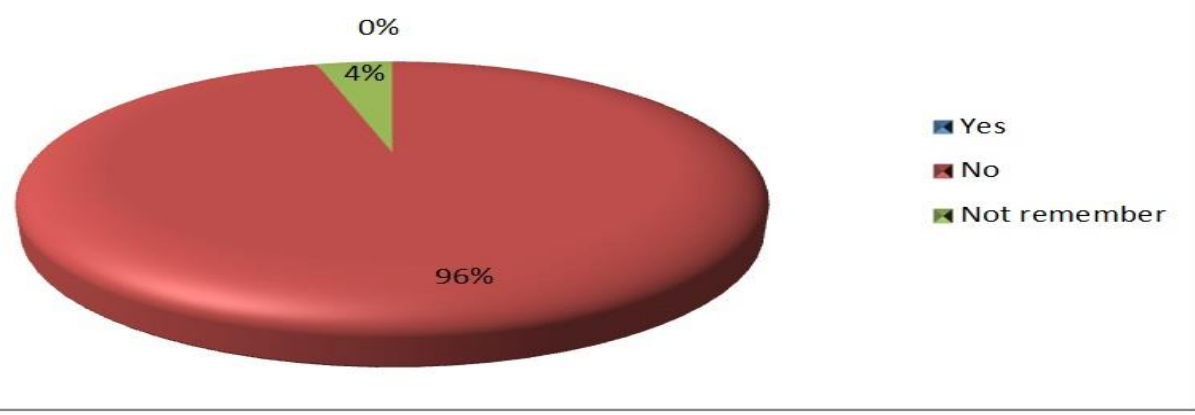

Figure (1): Percentage distribution of studied nurses regarding their attended training program about the care of the critically ill obese patient. 
Table (2): Distribution of demographic data of studied patients $(n=70)$.

\begin{tabular}{|c|c|c|}
\hline & No. $(n=70)$ & $\%$ \\
\hline \multicolumn{3}{|l|}{ Age } \\
\hline$>45$ & 16 & 22.9 \\
\hline $45-54$ & 33 & 47.1 \\
\hline$<54$ & 21 & 30.0 \\
\hline \multicolumn{3}{|l|}{ Sex } \\
\hline Male & 29 & 41.4 \\
\hline Female & 41 & 58.6 \\
\hline \multicolumn{3}{|l|}{ Diagnosis } \\
\hline Respiratory diseases & 26 & 37.1 \\
\hline Cardiac diseases & 25 & 35.7 \\
\hline Neurological diseases & 15 & 21.4 \\
\hline Trauma diseases & 4 & 5.8 \\
\hline \multicolumn{3}{|l|}{ Chronic disease } \\
\hline Diabetes mellitus & 7 & 10.0 \\
\hline Cardiac disease & 4 & 5.7 \\
\hline Hypertension & 12 & 17.1 \\
\hline Chronic obstructive pulmonary disorder & 16 & 22.9 \\
\hline Renal disease & 1 & 1.4 \\
\hline Diabetes mellitus; hypertension & 15 & 21.4 \\
\hline Hypertension; cardiac disease & 6 & 8.6 \\
\hline Diabetes mellitus; cardiac disease & 2 & 2.9 \\
\hline Diabetes mellitus, hypertension, cardiac disease & 7 & 10.0 \\
\hline \multicolumn{3}{|l|}{ BMI categories } \\
\hline $30-34.9$ & 14 & 15.6 \\
\hline $35-40$ & 57 & 63.3 \\
\hline More than 40 & 19 & 21.1 \\
\hline \multicolumn{3}{|l|}{ ICU unit } \\
\hline Trauma ICU & 35 & 50.0 \\
\hline General ICU & 13 & 18.6 \\
\hline Cardiac ICU & 12 & 17.1 \\
\hline Anesthesia ICU & 10 & 14.3 \\
\hline \multicolumn{3}{|l|}{ Calorie intake } \\
\hline High calorie intake & 52 & 74.3 \\
\hline Low calorie intake & 18 & 25.7 \\
\hline
\end{tabular}

Data described as (No. \& \%).

Table (3): Distribution of nurses obstacles during care of critically ill obese patients regarding equipment (n=90).

\begin{tabular}{|c|c|c|c|c|c|c|c|c|c|c|}
\hline \multirow{2}{*}{$\begin{array}{l}\text { Obstacles in care of obese patients } \\
\text { regarding equipment }\end{array}$} & \multicolumn{2}{|c|}{$\begin{array}{c}\text { Strongly } \\
\text { agree }\end{array}$} & \multicolumn{2}{|c|}{ Agree } & \multicolumn{2}{|c|}{ Undecided } & \multicolumn{2}{|c|}{ Disagree } & \multicolumn{2}{|c|}{$\begin{array}{l}\text { Strongly } \\
\text { disagree }\end{array}$} \\
\hline & No. & $\%$ & No. & $\%$ & No. & $\%$ & No. & $\%$ & No. & $\%$ \\
\hline Lifters and aids for lifting patients & 60 & 66.7 & 10 & 11.1 & 8 & 8.9 & 8 & 8.9 & 4 & 4.4 \\
\hline $\begin{array}{l}\text { Sphygmomanometers with } \\
\text { appropriate cuff size }\end{array}$ & 69 & 76.7 & 7 & 7.8 & 6 & 6.7 & 5 & 5.6 & 3 & 3.3 \\
\hline Patient gowns with appropriate size & 48 & 53.3 & 9 & 10.0 & 7 & 7.8 & 16 & 17.8 & 10 & 11.1 \\
\hline Bed sheets with appropriate size & 10 & 11.1 & 8 & 8.9 & 22 & 24.4 & 22 & 24.4 & 28 & 31.1 \\
\hline Wheelchairs with appropriate size & 45 & 50.0 & 10 & 11.1 & 8 & 8.9 & 21 & 23.3 & 6 & 6.7 \\
\hline Chairs with appropriate size & 46 & 51.1 & 6 & 6.7 & 14 & 15.6 & 17 & 18.9 & 7 & 7.8 \\
\hline Walkers for obese patient & 15 & 16.7 & 8 & 8.9 & 4 & 4.4 & 10 & 11.1 & 53 & 58.9 \\
\hline Bariatric bed & 54 & 60.0 & 6 & 6.7 & 8 & 8.9 & 6 & 6.7 & 16 & 17.8 \\
\hline Stretchers & 51 & 56.7 & 10 & 11.1 & 4 & 4.4 & 3 & 3.3 & 22 & 24.4 \\
\hline Others & \multicolumn{5}{|c|}{ No. } & \multicolumn{5}{|c|}{$\%$} \\
\hline *Bariatric mattress. & \multicolumn{5}{|c|}{7} & \multicolumn{5}{|c|}{7.8} \\
\hline
\end{tabular}

Data described as (No. \& \%). *Other obstacles in care of critically ill obese patients regarding equipment from the perspectives of nurses. 
Table (4): Distribution of nurses obstacles during care of critically ill obese patients regarding clinical practice ( $n=90$ ).

\begin{tabular}{|c|c|c|c|c|c|c|c|c|c|c|}
\hline \multirow{2}{*}{$\begin{array}{l}\text { Obstacles in care of obese } \\
\text { patients regarding clinical } \\
\text { practice }\end{array}$} & \multicolumn{2}{|c|}{$\begin{array}{l}\text { Strongly } \\
\text { agree }\end{array}$} & \multicolumn{2}{|c|}{ Agree } & \multicolumn{2}{|c|}{ Undecided } & \multicolumn{2}{|c|}{ Disagree } & \multicolumn{2}{|c|}{$\begin{array}{l}\text { Strongly } \\
\text { disagree }\end{array}$} \\
\hline & No. & $\%$ & No. & $\%$ & No. & $\%$ & No. & $\%$ & No. & $\%$ \\
\hline $\begin{array}{l}\text { Turning and repositioning } \\
\text { patients on the bed }\end{array}$ & 82 & 91.1 & 2 & 2.2 & 3 & 3.3 & 2 & 2.2 & 1 & 1.1 \\
\hline Blood pressure measurement & 69 & 76.7 & 6 & 6.7 & 7 & 7.8 & 4 & 4.4 & 4 & 4.4 \\
\hline $\begin{array}{l}\text { Transferring patients } \\
\text { between wards }\end{array}$ & 60 & 66.7 & 10 & 11.1 & 10 & 11.1 & 6 & 6.7 & 4 & 4.4 \\
\hline $\begin{array}{l}\text { Weaning patient from } \\
\text { mechanical ventilation }\end{array}$ & 13 & 14.4 & 25 & 27.8 & 19 & 21.1 & 19 & 21.1 & 14 & 15.6 \\
\hline Changing clothes & 7 & 7.8 & 18 & 20.0 & 20 & 22.2 & 8 & 8.9 & 37 & 41.1 \\
\hline Changing bed sheets & 5 & 5.6 & 24 & 26.7 & 14 & 15.6 & 5 & 5.6 & 42 & 46.7 \\
\hline $\begin{array}{l}\text { Bathing and hygiene care of } \\
\text { patient }\end{array}$ & 47 & 52.2 & 15 & 16.7 & 11 & 12.2 & 14 & 15.6 & 3 & 3.3 \\
\hline Mobilizing patients & 8 & 8.9 & 22 & 24.4 & 16 & 17.8 & 14 & 15.6 & 30 & 33.3 \\
\hline $\begin{array}{l}\text { Auscultating to listen to their } \\
\text { lung sounds, heart sounds } \\
\text { and bowel sound }\end{array}$ & 15 & 16.7 & 25 & 27.8 & 27 & 30.0 & 12 & 13.3 & 11 & 12.2 \\
\hline Hemodynamic monitoring & 46 & 51.1 & 10 & 11.1 & 8 & 8.9 & 14 & 15.6 & 12 & 13.3 \\
\hline Abdominal palpation & 21 & 23.3 & 20 & 22.2 & 24 & 26.7 & 13 & 14.4 & 12 & 13.3 \\
\hline $\begin{array}{l}\text { Cardiopulmonary } \\
\text { resuscitation }\end{array}$ & 45 & 50.0 & 14 & 15.6 & 10 & 11.1 & 18 & 20.0 & 3 & 3.3 \\
\hline $\begin{array}{l}\text { Insertion of peripheral line } \\
\text { (cannula) }\end{array}$ & 49 & 54.4 & 13 & 14.4 & 11 & 12.2 & 10 & 11.1 & 7 & 7.8 \\
\hline $\begin{array}{l}\text { Insertion of airway } \\
\text { management }\end{array}$ & 8 & 8.9 & 20 & 22.2 & 17 & 18.9 & 13 & 14.4 & 32 & 35.6 \\
\hline $\begin{array}{l}\text { Calculate calories required } \\
\text { by patient }\end{array}$ & 61 & 67.8 & 15 & 16.7 & 8 & 8.9 & 3 & 3.3 & 3 & 3.3 \\
\hline $\begin{array}{l}\text { Calculations, dosages, and } \\
\text { protocols of intravenous } \\
\text { medication }\end{array}$ & 46 & 51.1 & 15 & 16.7 & 17 & 18.9 & 8 & 8.9 & 4 & 4.4 \\
\hline Others & & & No. & & & & & $\%$ & & \\
\hline$*$ Dressing & & & 4 & & & & & $4.4 \%$ & & \\
\hline
\end{tabular}

Data described as (No. \& \%).*Other obstacles in care of critically ill obese patients regarding clinical practice from the perspective of nurses. 
Table (5): Distribution of nurses' priorities to improve care of critically ill obese patients $(\mathbf{n}=90)$.

\begin{tabular}{|c|c|c|c|c|c|c|c|c|c|c|}
\hline \multirow{2}{*}{$\begin{array}{l}\text { Priorities to improve care of } \\
\text { obese patients }\end{array}$} & \multicolumn{2}{|c|}{$\begin{array}{c}\text { Strongly } \\
\text { agree }\end{array}$} & \multicolumn{2}{|c|}{ Agree } & \multicolumn{2}{|c|}{ Undecided } & \multicolumn{2}{|c|}{ Disagree } & \multicolumn{2}{|c|}{$\begin{array}{l}\begin{array}{l}\text { Strongly } \\
\text { disagree }\end{array} \\
\end{array}$} \\
\hline & No. & $\%$ & No. & $\%$ & No. & $\%$ & No. & $\%$ & & $\%$ \\
\hline $\begin{array}{l}\text { Provision of appropriate and } \\
\text { adequate comfort and care } \\
\text { equipment. }\end{array}$ & 49 & 54.4 & 14 & 15.6 & 14 & 15.6 & 8 & 8.9 & 5 & 5.6 \\
\hline $\begin{array}{l}\text { Use of experienced personnel for } \\
\text { difficult and complicated } \\
\text { procedure in care of obese } \\
\text { patients. }\end{array}$ & 48 & 53.3 & 16 & 17.8 & 12 & 13.3 & 10 & 11.1 & 4 & 4.4 \\
\hline $\begin{array}{l}\text { Supply of enough personnel for } \\
\text { help and providing more care to } \\
\text { obese patients. }\end{array}$ & 58 & 64.4 & 14 & 15.6 & 4 & 4.4 & 8 & 8.9 & 6 & 6.7 \\
\hline $\begin{array}{l}\text { Training program in care of obese } \\
\text { patients. }\end{array}$ & 56 & 62.2 & 15 & 16.7 & 6 & 6.7 & 7 & 7.8 & 6 & 6.7 \\
\hline $\begin{array}{l}\text { Provide clinical guidelines, } \\
\text { practice standards and other } \\
\text { resources to assist nurses in care of } \\
\text { obese patient. }\end{array}$ & 52 & 57.8 & 17 & 18.9 & 7 & 7.8 & 7 & 7.8 & 7 & 7.8 \\
\hline Others & \multicolumn{5}{|c|}{ No. } & \multicolumn{5}{|c|}{$\%$} \\
\hline $\begin{array}{l}\text { * Add care of critically ill obese } \\
\text { patient to nursing curriculum. }\end{array}$ & \multicolumn{5}{|c|}{3} & \multicolumn{5}{|c|}{$3.3 \%$} \\
\hline
\end{tabular}

Data described as (No. \& \%). *Other priorities to improve the care of critically ill obese patients from the perspective of nurses.

Table (6): Relationship between age and obstacles in the care of obese patients regarding equipment among studied nurses.

\begin{tabular}{|c|c|c|c|c|c|c|c|}
\hline \multirow{3}{*}{$\begin{array}{l}\text { Obstacles in care of obese patient } \\
\text { regarding equipment }\end{array}$} & \multicolumn{7}{|c|}{ Age } \\
\hline & \multicolumn{2}{|c|}{$<24(n=30)$} & \multicolumn{2}{|c|}{ 24-30 $(n=57)$} & \multicolumn{2}{|c|}{$>30(n=3)$} & \multirow{2}{*}{$\begin{array}{c}P \\
\text { value }\end{array}$} \\
\hline & $\mathbf{M}$ & SD & $\mathbf{M}$ & SD & $\mathbf{M}$ & SD & \\
\hline Lifters and aids for lifting patients & 3.80 & 1.375 & 4.53 & 1.020 & 4.00 & 1.732 & .025 \\
\hline $\begin{array}{l}\text { Sphygmomanometer with appropriate } \\
\text { cuff size }\end{array}$ & 4.27 & 1.337 & 4.58 & .905 & 5.00 & .000 & .302 \\
\hline Patient gowns with appropriate size & 3.67 & 1.561 & 3.95 & 1.420 & 1.33 & .577 & $.011 *$ \\
\hline Bed sheets with appropriate size & 2.50 & 1.280 & 2.42 & 1.309 & 2.33 & 2.309 & .956 \\
\hline Wheelchairs with appropriate size & 3.70 & 1.489 & 3.81 & 1.469 & 3.67 & .577 & .942 \\
\hline Chairs with appropriate size & 3.43 & 1.501 & 3.93 & 1.374 & 3.33 & 2.082 & .278 \\
\hline Walkers for obese patient & 2.43 & 1.675 & 1.82 & 1.390 & 5.00 & .000 & $.001^{\circ}$ \\
\hline Bariatric bed & 3.63 & 1.542 & 4.00 & 1.615 & 3.00 & 2.082 & .392 \\
\hline Stretchers & 3.73 & 1.617 & 3.74 & 1.758 & 3.33 & .707 & .924 \\
\hline
\end{tabular}

$P$-value was *statistically significant when less than 0.05 .

Table (1): It shows that $62.2 \%$ of the studied nurses were in the age group 24-30 years old and their main age $25.2 \pm 4.1$, all of them were females, $61.1 \%$ were married, $58.9 \%$ had working experience less than 4 years and $63.3 \%$ had a nursing diploma.

Figure (1): It explains that $95.6 \%$ of studied nurses didn't attend any training about the care of critically ill obese patients.

Table (2): It shows that $47.1 \%$ of the studied patients were in the age group 45-54 years old, $58.6 \%$ of them were females, $37.1 \%$ with respiratory diseases and $35.7 \%$ with cardiac diseases, $57.1 \%$ hypertensive, $50.0 \%$ of them in trauma ICU, $74.3 \%$ had high-calorie intake and $63.3 \%$ with BMI between 35-39.9.

Table (3): It shows nurses' obstacles in care of critically ill obese patients regarding equipment; the most reported obstacles were related to the lack of proper sphygmomanometers cuff size with $76.7 \%$, followed by lifters and aids with $66.7 \%$, bariatric bed with $60.0 \%$, stretchers with $56.7 \%$, gowns, chairs and wheelchairs with $53.3 \%, 51.1 \%$ and $50.0 \%$ respectively.

Table (4): It describes nurses' obstacles in the care of critically ill obese patients regarding clinical practice; the most reported obstacles were turning 
and repositioning patients on the bed with $91.1 \%$. After that blood pressure measurement with $76.7 \%$, calculate calories required by the patient with $67.8 \%$, transferring patients between wards, insertion of peripheral line, bathing and hygiene care with $66.7 \%$, 54.4\%, and $52.2 \%$ respectively, hemodynamic monitoring and calculations, dosages, and protocols of intravenous medication with $51.1 \%$ and cardiopulmonary resuscitation with $50.0 \%$.

Table (5): It shows the priorities of nurses to improve the care of critically ill obese patients. The most-reported priorities were related to the provision of appropriate and adequate comfort and care equipment with $64.4 \%$, followed by a training program in care of obese patients with $62.2 \%$, provide clinical guidelines, practice standards, and other resources to assist nurses in the care of the obese patient in complex and acute situations with $57.8 \%$, provision of appropriate and adequate comfort and care equipment with $54.4 \%$ and use of experienced personnel for a difficult and complicated procedure in care of obese patients with $53.3 \%$.

Table (6): It shows that there was a statistically significant difference between critical care nurses' age and obstacles related to lifters and aids for lifting patient $(\mathrm{P} .=.025)$, patient gowns with the appropriate size $(\mathrm{P} .=.011)$, and walkers for obese patients $(\mathrm{P} .=.001)$.

\section{Discussion}

Nurses play a critical role in providing quality care to their critically ill obese patients. Overarching guiding principles help the nurse to provide safe patient care and preventing caregiver injury. Guiding principles such as explain best nursing practices and provide practical information about obese patient care on a variety of topics, including appropriate skin and wound care, attention to ventilation, assessment of vital signs, drug absorption, mobilizing, and transferring in a manner that is safe for both the patient and the nurse (Rowen, 2009).

This discussion will cover the main result findings as follow

The result of the present study showed that more than half of nurses were at the age group between 24 and $30 y e a r s$, female, married, years of experience of more than half of them less than 4 years, holds nursing diploma and institute is the highest proportion and more than half of them within normal weight. In my opinion, these results may be explained by a healthier lifestyle of nurses compared to the general population, and most of the nurses were female that may be due to nursing schools and faculty of nursing newly inserted the male students in their study.
Regarding that more than half of the nurses were in the age group between 24 and 30years, I think this is maybe due to that middle age are more experienced, active and get more involved in high complexity health care field as intensive care units.

These results were in agreement with Shea \& Gagnon, (2015), who reported that the majority of nurses were female while the male was less than one third, nurses with the age group of 25-29 years had the highest percentage. On the other hand, disagree with our study result in that the majority of nurses who are working in ICU generally had a bachelor's degree in nursing.

In relation to attending any previous training program, the majority of nurses didn't receive any training courses. I think this might due to the hospital have no staff development program related to the care of a critically ill obese patient. This result was supported by (Bucher et al., 2018), who said that physicians and nurses lacked confidence and training to care of patients with obesity and more than half of them had the feeling that they didn't have adequate training.

The current study was clarified that more than half of the obese patients were female. In this line study conducted in Egypt by (Alebshehy et al., 2016) showed that there was a huge burden of obesity among women in Egypt. The prevalence of obesity is almost double among females as compared to males. As regard that more than half of them were hypertensive and less than half in the age group 4554-year-olds. This study result was in agreement with Kearns et al., (2018), who stated that there was a direct association between increasing BMI and increasing prevalence of the related chronic disease. The most prevalent chronic conditions were hypertension. Regarding the age obesity was highest in 45-54-year-olds.

In the current study as regards more than one-third of the obese patients were diagnosed of respiratory and cardiac disease. This was in line with Kinlen et al., (2018) in their study about complications of obesity showed that obesity is associated with increased numerous complications including heart disease and respiratory disease. Even low levels of overweight are associated with an increased risk of complication. In this study, the nurses' obstacles in the care of obese patients regarding equipment were assessed. The most-reported nurses' challenges were related to the lack of proper sphygmomanometers cuff size to measure blood pressure for the obese patient. From the researcher's point of view, that may due to the available cuff size is a standard cuff and there is no cuff appropriate for obese patients in the hospital. These results supported by Foroozesh et al., (2017) in their study about challenges in the nursing care of 
morbidly obese patients, who mentioned that the most reported problems related to equipment were lack of proper blood pressure cuff.

Also, this result was in line with the study conducted by Veiga et al., (2009), who stated that the large arm circumference range, requiring several cuff sizes to avoid blood pressure measurements errors and hypertension misdiagnosis. Moreover Walsh \& Kuhn (2017) mentioned that selecting an inappropriate cuff size is a common and significant source of error in blood pressure measurement.

The present study found that more than two-thirds of nurses reported that lifters and aids for lifting obese patients were a big challenge that interferes with patient care. These results were in line with the study conducted by Miles et al., (2012), who showed that equipment concerns seemed to be a major barrier to nursing. Problems with the availability of lifters and other bariatric equipment begin to rise with increased number of obese patient.

As regarding bariatric beds, more than half of nurses thought that the bariatric bed should be available for the obese patient. In my opinion that may be related to, if a patient's bed is too small, it will be no sufficient space for the patient to be turned even once. Also, a bed that is too narrow may increase the likelihood that patients could roll past the edge of the bed and fall. The result of the present study supported by Wiggermann et al., (2017) who stated that nurses should consider placing patients that are unable to laterally reposition themselves on a wider bed when BMI is greater than $35 \mathrm{~kg} / \mathrm{m}^{2}$. Also, nurses must consider placing all patients greater than $45 \mathrm{~kg} / \mathrm{m}^{2}$ on a wider bed regardless of mobility.

In the current study stretchers were one of the obstacles that more than half of nurses suffering from. I think that due to the increase in weight and the big size of the obese patient will make nurse struggle to keep patient on small size stretchers. In this respect Hammond (2013) stated that nursing faces a variety of unique challenges one of them that transport devices such as stretchers for use with obese patients are not feasible.

The study results revealed that more than half of nurses had difficulty to find patient gowns of appropriate size. From the researcher's point of view that may be due to even, they found a big gown it was not suitable for very obese patients and it will cover only the front part of them. This matches with Blackett et al., (2011) who mentioned that the larger sized patient items such as gowns need to be available for patients so that they can care for them with dignity and safety.

The current study demonstrated that half of the nurses reported that chairs and wheelchairs of appropriate size are not available for the obese patient.This result was in agreement with Phelan et al., (2015) who reported that chairs with armrests can be uncomfortable or too small. These chairs are often designed for use with smaller patients. Also, this result was compatible with Hales et al., (2018) who reported that the physical shape of obese patients did not appropriately fit the different equipment such as a wheelchair. Nurses modify available wheelchair to create wider spaces.

In obstacles related to clinical practice, the present study found that turning and repositioning patients on the bed was reported by the majority of nurses. From the researcher's point of view, this may be related to all-time nurses want to provide optimal care for the obese patient and they turning the obese patient every two hours to prevent bedsores, but they suffer at the end of a shift from back pain and most. In the same line Johnson \& Meyenburg (2009) who reported that position critically ill patients up in bed for turning to the side is challenging and places caregivers at high risk for injury.

Also, Randall et al., (2009) who mentioned that the mobilization of morbidly obese patients poses significant physical challenges to healthcare providers. Manual mobilization of morbidly obese patients increases the risk of caregiver injury. Moreover, Choi \& Brings (2016) who mentioned in their study about Work-related musculoskeletal risks, that one of the challenges that nurses and nursing assistants encounter on a daily basis are overweight or obese patient lifting and repositioning.

This study revealed that blood pressure measurement difficulty was reported by most of the nurses as one of their big challenges. This result was consistent with a study conducted by McFarlane, (2012) who mentioned that measuring blood pressure in patients with obesity presents a number of challenges for nurses centered on the selection of the right size cuff. Blood pressure measurements taken with a standard cuff instead of a large cuff in obese patients are significantly higher. In another study completed by Verkhovsky et al., (2018) in a sample of 30 adults with body mass index more than or equal to $30 \mathrm{~kg} / \mathrm{m} 2$ about blood pressure measurement, who reported that accurate blood pressure measurement in an obese patient through using upper arm, non-invasive blood pressure measurement is technically challenging for nurses.

The current study results revealed that more than two-thirds of nurses reported calculating calories required by the patient as one of their challenges in the care of obese patients. In my opinion that may be due to there is no equation, techniques, and protocols available in their unit to help them in calculating calories required by obese patients. This result consistent with Port \& Apovian(2010) who showed 
that there are many obstacles that limit the provision of nutrition support in the obese patient. Calculating energy needs accurately is extremely problematic due to a lack of reliable prediction equations and wide variability in body composition among obese patients.

Similarly, the current study was in line with Dickerson et al., (2017) who stated that nutrition assessment of the obese patient is challenging because conventional physical assessment techniques are not precise. In addition, our result was in agreement with those of Nelson \& Way (2012) who reported that one of the most difficult aspects in the care of obese patients is nutrition support and calculating the metabolic needs of obese patients.

The result of the present study showed that obstacles in transferring obese patients between wards were reported by more than two-thirds of nurses. In this respect Palmer (2013) who stated that moving and handling patient is a potentially dangerous task, which is made even more complex when the patient who requires transferring is obese. In addition, our result was in agreement with those of Broome et al., (2015) who reported that bariatric patients can present unique challenges for nurses. The first challenge occurred during the transfer of patients from unit to unit. Nurses required more time and staff members were to complete transferring and positioning.

The current study revealed that more than half of nurses reported that insertion of a peripheral line (cannula) was a big obstacle for them. From the researcher's point of view, this result may be due to that most times obese patients had difficult venous access. Furthermore, obese patients' veins are neither visible nor palpable which leads to difficult intravenous access for nurses. This result was compatible with Prakash et al., (2015) who showed that in obese patients establishing peripheral intravenous access proved difficult ,frustrating, tedious and time-consuming procedure.

In relation to bathing and hygiene care of an obese patient, this study clarified that more than half of nurses mentioned it as one of their obstacles. I think that due to nurses spent more time in bathing and the nature of the intensive care unit which needs you to be alert all time, but bathing will take a lot of time and this will interfere with the concentration of nurses and it is a time-consuming process. This result was compatible with Pokorny et al., (2009) who reported that toileting and bathing were noted as particularly problematic for nurses. Caregivers and obese patients experience a high degree of fatigue when performing or assisting in bathing.

Hemodynamic monitoring is one of the obstacles reported by more than half of nurses, these findings are supported by a study conducted by Jamadarkhana et al., (2014) who reported that assessing and monitoring the circulation of a critically ill obese patient is another challenging task. It may be difficult for nurses to palpate the peripheral pulses and obtain arterial pressure using a standard cuff. Moreover, an electrocardiogram may show lowvoltage complexes due to the thick adipose tissue covering the chest wall.

Regarding the calculations, dosages, and protocols of intravenous medication were reported by more than half of nurses. From the researcher's point of view, this may be related to most intravenous medication protocols in ICU are for the patient with normal weight. This result consistent with Bajwa et al., (2012) who reported that there are no universal guidelines and protocols for the administration of dosing schedules in obese patients and evidencebased methods for determining appropriate dosing strategies are lacking.

In relation to cardiopulmonary resuscitation, the present study demonstrated that half of the nurses mentioned cardiopulmonary resuscitation as one of their obstacles in care of obese patients at intensive care units. In this respect Tellson et al., (2017) stated that compression quality performed by a health care provider is lower when performed on obese and morbidly obese adult. Similarly, the current study was consistent with Edelson et al., (2018) who reported that more obese patients trended toward worse outcomes from cardiac arrest than patients with lower body mass index.

In addition, this study result was in agreement with Gray \& Dieudonne (2018) who stated that patients with obesity poses a unique challenge to healthcare providers. Adiposity affects each of the phases of resuscitation such as airway management, respiratory mechanics, monitoring and support, circulatory monitoring, and optimization.

Regarding the relation between age of studied nurses and obstacles in care of critically ill obese patient regarding equipment, the present study showed that there was a statistically significant difference between studied nurses' age and obstacles related to lifters and aids for lifting patient, patient gowns, and walkers for obese patients. This result may be owing to the fact that there was the effect of age on obstacles related to equipment.

Our study result shows that from the perspective of nurses the priorities in the care of obese patients include a supply of enough personnel for help and providing more care to obese patients, a training program in care of obese patients, provide clinical guidelines, practice standards, and other resources to assist nurses in the care of an obese patient, provision of appropriate and adequate comfort and care 
equipment, use of experienced personnel for a difficult and complicated procedure in care of obese patients were reported by more than the half of nurses.

This result is supported by Berrios, (2016) who reported that health care facilities must be prepared to care for patients of any weight and size. This preparation includes conducting structural assessments of facilities, ensuring that support equipment is readily available and that nursing staff is trained to use the equipment, and providing enough nursing staff and adequate education on the clinical differences between obese and non-obese patients in medical and nursing management.

\section{Conclusion}

Based on the findings of the present study, nurses' obstacles in the care of critically ill obese patients are increase along with an increased number of obese patients. Most nurses' obstacles regarding equipment were related to lack of proper sphygmomanometers cuff size, lifters, and aids, bariatric bed, stretchers, gowns, chairs, and wheelchairs. According to clinical practice the most nurses' obstacles were turning and repositioning, blood pressure measurement, calculate calories, transferring patients, insertion of peripheral line, bathing and hygiene care, hemodynamic monitoring, calculations, dosages, and protocols of intravenous medication and cardiopulmonary resuscitation.

\section{Recommendation}

1. Provide training courses for critical care nurses regarding the care of critically ill obese patients.

2. Provide adequate nursing staff and ratio between nurses and patient in critical care unit to reach one to one.

3. Standard equipping must be found in critical care units.

4. The nursing curriculum should contain care of obese patients to improve nursing care of these patients.

5. Availability of special equipment for caring for obese patients as standard protocol.

6. Provide clinical guidelines, practice standards, and other resources to assist nurses in the care of obese patients.

\section{Reference}

- Alebshehy, R., Shuaib, N., Mbako, J., Barffo, D., \& Nuotol, R., (2016): Determinant analysis of obesity among adult females in Egypt, The Egyptian Journal of Hospital Medicine, Vol. (65), No.(1), Pp662-669.
- Bajwa, S., Sehgal, V., \& Bajwa, S., (2012): Clinical and critical care concerns in severely ill obese patient, Indian Journal of Endocrinology and Metabolism, Vol. (16), No.(5), Pp740.

- Berrios, L., (2016): The ABCDs of managing morbidly obese patients in intensive care units, Critical Care Nurse, Vol. (36), No.(5), Pp1726.

- Blackett, A., Gallagher, S., Dugan, S., Gates, J., Henn, T., Kennedy-Evans, K., \& Lutze, J., (2011): Caring for persons with bariatric health care issues: a primer for the WOC nurse, Journal of Wound Ostomy \& Continence Nursing, Vol. (38), No.(2), Pp133-138.

- Broome, C., Ayala, E., Georgeson, K., Heidrich, S., Karnes, K., \& Wells, J., (2015): Nursing care of the super bariatric patient: challenges and lessons learned, Rehabilitation Nursing, Vol. (40), No.(2), Pp92-99.

- Bucher Della Torre, S., Courvoisier, D., Saldarriaga, A., Martin, X., \& Farpour-Lambert, N., (2018): Knowledge, attitudes, representations and declared practices of nurses and physicians about obesity in a university hospital: training is essential, Clinical obesity, Vol. (8), No.(2), Pp122-130.

- Cheyenne, B., \& Michael, B., (2018): The world's most overweight countries, online https://247wallst.com/special-report at 11/7/2018.

- Choi, S., \& Brings, K., (2016): Work-related musculoskeletal risks associated with nurses and nursing assistants handling overweight and obese patients: A literature review, Work, Vol. (53), No. (2), Pp439-448.

- Dickerson, R., Patel, J., \& McClain, C., (2017): Protein and calorie requirements associated with the presence of obesity, Nutrition in Clinical Practice, Vol. (32), No.(1_suppl) Pp86S-93S.

- Edelson, D., Abella, B., Kim, S., Hoek, T., \& Becker, L., (2006): The effects of obesity on CPR quality and survival after cardiac arrest, Circulation, Vol. (114), No.(18), PpII.

- Foroozesh, R., Sadati, L., Nosrati, S., Karami, S., Beyrami, A., \& Fasihi, T., (2017): Challenges in nursing care of morbidly obese patients: Nurses' viewpoints, Journal of Minimally Invasive Surgical Sciences, Vol. (6), No.(2), Pp2-7.

- Gray, S., \& Dieudonne, B., (2018): Optimizing care for trauma patients with obesity, Cureus, Vol. (10), No. (7), Pp1-8.

- Hales, C., Coombs, M., \& de Vries, K., (2018): The challenges in caring for morbidly obese patients in Intensive Care: A focused ethnographic study, Australian Critical Care, Vol. (31), No.(1), Pp37-41. 
- Hammond, K., (2013): Practical issues in the surgical care of the obese patient, Ochsner Journal, Vol. (13), No. (2), Pp224-227.

- Jaacks, L., Vandevijvere, S., Pan, A., McGowan, C., Wallace, C., Imamura, F., \& Ezzati, M., (2019): The obesity transition: stages of the global epidemic, The lancet Diabetes \& endocrinology, Vol. (7), No.(3), Pp231-240.

- Jamadarkhana, S., Mallick, A., \& Bodenham, A., (2014): Intensive care management of morbidly obese patients. Continuing Education in Anaesthesia, Critical Care \& Pain, Vol. (14), No(2), Pp73-78.

- Johnson, K., \& Meyenburg, T., (2009): Physiological rationale and current evidence for therapeutic positioning of critically ill patients, AACN advanced critical care, Vol. (20), No.(3), Pp228-240.

- Kearns, K., Dee, A., Fitzgerald, A., Doherty, E., \& Perry, I., (2014): Chronic disease burden associated with overweight and obesity in Ireland: the effects of a small BMI reduction at population level, BMC public health, Vol. (14), No.(1), Pp110.

- Kinlen, D., Cody, D., \& O'Shea, D., (2018): Complications of obesity, QJM: An International Journal of Medicine, Vol. (111), No. (7), Pp437443.

- Lumley, E., Homer, C., Palfreyman, S., Shackley, P., \& Tod, A., (2015): A qualitative study to explore the attitude of clinical staff to the challenges of caring for obese patients, Journal of clinical nursing, Vol. (24), No.(23), Pp3594-3604.

- Luy, S., \& Dampil, O., (2018): Comparison of the Harris-Benedict equation, bioelectrical impedance analysis, and indirect calorimetry for measurement of basal metabolic rate among adult obese Filipino patients with prediabetes or type 2 diabetes mellitus, Journal of the ASEAN Federation of Endocrine Societies, Vol. (33), No.(2), Pp152.

- Malelelo-Ndou, H., Ramathuba, D., \& Netshisaulu, K., (2019): Challenges experienced by health care professionals working in resourcepoor intensive care settings in the Limpopo province of South Africa, Curationis, Vol. (42), No.(1), Pp1-8.

- El Solh, A., (2012): Critical care management of the obese Patient, $1^{\text {st }}$ edition, chapter 14 , West Sussex: John Wiley \& Sons.

- McFarlane, J., (2012): Blood pressure measurement in obese patients, Critical care nurse, Vol. (32), No. (6), Pp70-73.

- Miles, J., Anderson, D., Engelke, M., Kirkpatrick, M., Pories, M., Waters, W., \& Rose, M. (2012): Barriers to transition of obese patients from hospital to community, The American journal of managed care, Vol. (18), No.(6), Pp234.

- Nelson, B., \& Van Way, C., (2012): Nutrition in the critically ill obese patient, Missouri medicine, Vol. (109), No.(5), Pp393-396.

- Palmer, R., (2004): Moving and handling bariatric patients safely: a case study, International Journal of Therapy and Rehabilitation, Vol. (11), No.(1), Pp 31-33.

- Phelan, S., Burgess, D., Yeazel, M., Hellerstedt, W., Griffin, J., \& Ryn, M., (2015): Obesity stigma and patient care, Obes Rev, Vol. (16), Pp319-326.

- Pokorny, M., Scott, E., Rose, M., Baker, G., Swanson, M., Waters, W., \& Drake, D., (2009): Challenges in caring for morbidly obese patients, Home Healthcare Now, Vol. (27), No.(1), Pp43-52.

- Port, A., \& Apovian, C., (2010): Metabolic support of the obese intensive care unit patient: a current perspective, Current opinion in clinical nutrition and metabolic care, Vol. (13), No.(2), Pp184-191.

- Prakash, S., Arora, G., \& Rani, H., (2015): Peripheral venous access in the obese patient, Indian Journal of Anesthesia, Vol. (59), No.(10), Pp692-693.

- Randall, S., Pories, W., Pearson, A., \& Drake, D., (2009): Expanded Occupational Safety and Health Administration $300 \log$ as metric for bariatric patient-handling staff injuries, Surgery for Obesity and Related Diseases, Vol. (5), No.(4), Pp463-468.

- Robstad, N., Söderhamn, U., \& Fegran, L., (2018): Intensive care nurses' experiences of caring for obese intensive care patients: A hermeneutic study, Journal of clinical nursing, Vol. (27), No.(1), Pp386-395.

- Rowen, L., (2009): Overview and summary: Obesity on the rise: What can nurses do?, OJIN: The Online Journal of Issues in Nursing, Vol. (14),No.(1), Pp2-4.

- Shea, J., \& Gagnon, M., (2015): Working with patients living with obesity in the intensive care unit: a study of nurses' experiences, ANS. Advances in nursing science, Vol. (38), No.(3), Pp30-40.

- Tellson, A., Qin, H., Erwin, K., \& Houston, S., (2017): Efficacy of acute care health care providers in cardiopulmonary resuscitation compressions in normal and obese adult simulation manikins, Baylor University Medical Center Proceedings, Vol. (30), No.(4), Pp415-418. 
- Veiga, E., Arcuri, E., Cloutier, L., \& Santos, J., (2009): Blood pressure measurement: arm circumference and cuff size availability. Revista Latino-Americana de enfermagem, Vol. (17), No. (4), Pp455-461.

- Verkhovsky, A., Smit, M., Levin, A., \& Coetzee, J. (2018): Blood pressure measurement in obese patients: non-invasive proximal forearm versus direct intra-arterial measurements, Southern African Journal of Anaesthesia and Analgesia, Vol. (24), No.(3), Pp70-74.

- Walsh, M., Kuhn, T., Holmstrup, M., \& Jensen, B., (2017): Miscuffing Results in Blood Pressure Measurement Error and Misclassification, Keystone Journal of Undergraduate Research, Vol. (4), No.(1), Pp29-35.

- Wiggermann, N., Smith, K., \& Kumpar, D., (2017): What bed size does a patient need? The relationship between body mass index and space required to turn in bed. Nursing Research, Vol. (66), No. (6), Pp483- 489.

- World health organization (2020): Obesity, online https://www.who.int/topics/obesity/en/. at $(13 / 12 / 2020)$ 